\title{
Solid phase extraction for removal of matrix effects in lipophilic marine toxin analysis by liquid chromatography-tandem mass spectrometry
}

\author{
Arjen Gerssen - Mairead A. McElhinney • \\ Patrick P. J. Mulder • Ronel Bire • Philipp Hess • \\ Jacob de Boer
}

Received: 30 January 2009 /Revised: 2 April 2009/Accepted: 2 April 2009/Published online: 24 April 2009

(C) The Author(s) 2009. This article is published with open access at Springerlink.com

\begin{abstract}
The potential of solid phase extraction (SPE) clean-up has been assessed to reduce matrix effects (signal suppression or enhancement) in the liquid chromatographytandem mass spectrometry (LC-MS/MS) analysis of lipophilic marine toxins. A large array of ion-exchange, silica-based, and mixed-function SPE sorbents was tested. Polymeric sorbents were found to retain most of the toxins. Optimization experiments were carried out to maximize recoveries and the effectiveness of the clean-up. In LC-MS/ MS analysis, the observed matrix effects can depend on the chromatographic conditions used, therefore, two different
\end{abstract}

A. Gerssen $(\bowtie) \cdot$ P. P. J. Mulder

RIKILT - Institute of Food Safety,

Bornsesteeg 45, 6708 PD,

Wageningen, The Netherlands

e-mail: Arjen.Gerssen@wur.nl

M. A. McElhinney $\cdot$ R. Bire $\cdot$ P. Hess

Marine Institute-Biotoxins Chemistry,

Rinville, Oranmore,

Co. Galway, Ireland

J. de Boer

VU University - Institute for Environmental Studies,

De Boelelaan 1087,

$1081 \mathrm{HV}$, Amsterdam, The Netherlands

Present Address:

R. Bire

AFSSA-LERQAP,

23 Avenue du Général de Gaulle,

94706 Maisons-Alfort, France

Present Address:

P. Hess

Ifremer,

Rue de l'île d'Yeu,

44311 Nantes, France
HPLC methods were tested, using either an acidic or an alkaline mobile phase. The recovery of the optimized SPE protocol was around $90 \%$ for all toxins studied and no break-through was observed. The matrix effects were determined by comparing signal response from toxins spiked in crude and SPE-cleaned extracts with those derived from toxins prepared in methanol. In crude extracts, all toxins suffered from matrix effects, although in varying amounts. The most serious effects were observed for okadaic acid (OA) and pectenotoxin-2 (PTX2) in the positive electrospray ionization mode $\left(\mathrm{ESI}^{+}\right)$. SPE clean-up on polymeric sorbents in combination with the alkaline LC method resulted in a substantial reduction of matrix effects to less than $15 \%$ (apparent recovery between 85 and 115\%) for OA, yessotoxin (YTX) in ESI ${ }^{-}$and azaspiracid-1 (AZA1), PTX2, 13desmethyl spirolides C (SPX1), and gymnodimine (GYM) in $\mathrm{ESI}^{+}$. In combination with the acidic LC method, the matrix effects after SPE were also reduced but nevertheless approximately $30 \%$ of the matrix effects remained for PTX2, SPX1, and GYM in $\mathrm{ESI}^{+}$. It was concluded that SPE of methanolic shellfish extracts can be very useful for reduction of matrix effects. However, the type of LC and MS methods used is also of great importance. SPE on polymeric sorbents in combination with LC under alkaline conditions was found the most effective method.

Keywords Lipophilic marine toxins .

Solid phase extraction · Shellfish · Matrix effects

\section{Introduction}

Bivalves such as mussels, scallops, and oysters are filterfeeding organisms that can accumulate marine biotoxins 
produced by certain algae. The most common intoxications in Europe caused by the consumption of shellfish contaminated with marine toxins are diarrhetic shellfish poisoning (DSP), and to a lesser degree, paralytic shellfish poisoning (PSP). Toxins responsible for DSP intoxication belong to the group of the lipophilic marine biotoxins. In this paper, five different groups of lipophilic marine biotoxins are considered: the first group is the already mentioned DSP toxins of which the predominant toxins are okadaic acid (OA), dinophysistoxin-1 (DTX1), dinophysistoxin-2 (DTX2), and dinophysistoxin-3 (DTX3) (Fig. 1a). DTX3 is a collective term for acyl-esterified forms of $\mathrm{OA}$ and DTX1 and DTX2. DSP toxins cause diarrhea, nausea, vomiting, and abdominal cramps [1,2]. The second group is the yessotoxins (YTXs; Fig. 1b). YTXs have an adverse effect on the cardiac muscle cells in mice, but intoxications in humans so far have not been reported [3, 4]. The third group is the azaspiracids (AZAs; Fig. 1c), in which AZA1, -2 and -3 are the predominant toxins. Azaspiracids show adverse effects comparable to OA and DTXs; nausea, diarrhea, stomach cramps, etc. Although the adverse effects are comparable to those of DSP, the mode of action of AZAs is different and only partially elucidated $[5,6]$. The fourth group is the pectenotoxins (PTXs; Fig. 1d). The diarrhetic effects of PTXs are not clear and toxicity is only observed after intraperitoneal injection in mice $[7,8]$. The fifth group is the spiroimine toxins; spirolides (SPXs) and gymnodimine (GYM; Fig. 1e). These toxins show adverse neurological effects on the respiratory tract, comparable with saxitoxin (PSP toxin). The spiroimine toxins can cause death of mice within minutes after intraperitoneal injection [9].

EU regulation prescribes which lipophilic toxins should be monitored and determined in the edible parts of shellfish [10]. The permitted levels for the sum of OA, DTXs, and PTXs is set at $160 \mu \mathrm{g} \mathrm{kg}^{-1}$, the sum of relevant YTXs is set at a total of $1 \mathrm{mg} \mathrm{kg}^{-1}$ and the sum of relevant AZAs at $160 \mu \mathrm{g} \mathrm{kg}^{-1}[10]$. The spiroimines are currently not regulated under EU legislation, but may become regulated in the future [11]. Mouse or rat bioassay is the official control method for lipophilic marine toxins in shellfish (alternative methods may be used if they provide an equivalent level of shellfish consumer protection as provided by the bioassay and have been validated to international protocols). The animal assays have some serious drawbacks with respect to sensitivity, detectability of the individual toxins and in relation to animal welfare and ethics. In recent years, analytical methods based on liquid chromatography (LC) coupled to mass spectrometry (MS) have been developed as an alternative for the detection of lipophilic marine toxins in crude methanolic shellfish extracts [12-15]. However, it is well known that in LC-MS/MS analysis, matrix effects (ion suppression or ion enhancement) can lead to an under- or overestimation of the concentration. In order to overcome matrix effects, different approaches can be used, including internal standards, standard addition or the removal of matrix effects by various clean-up techniques. Unfortunately, in the field of
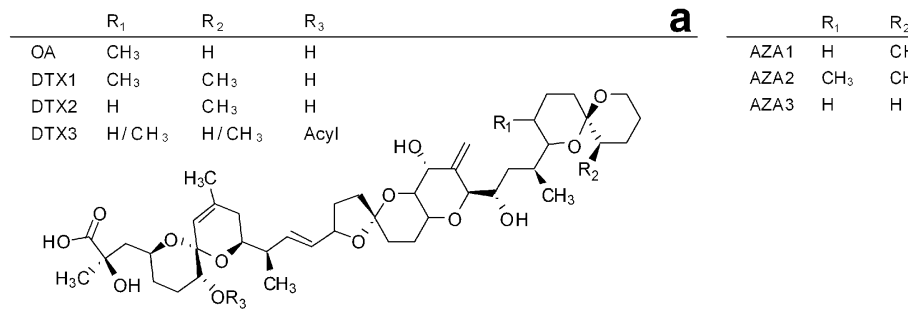

b
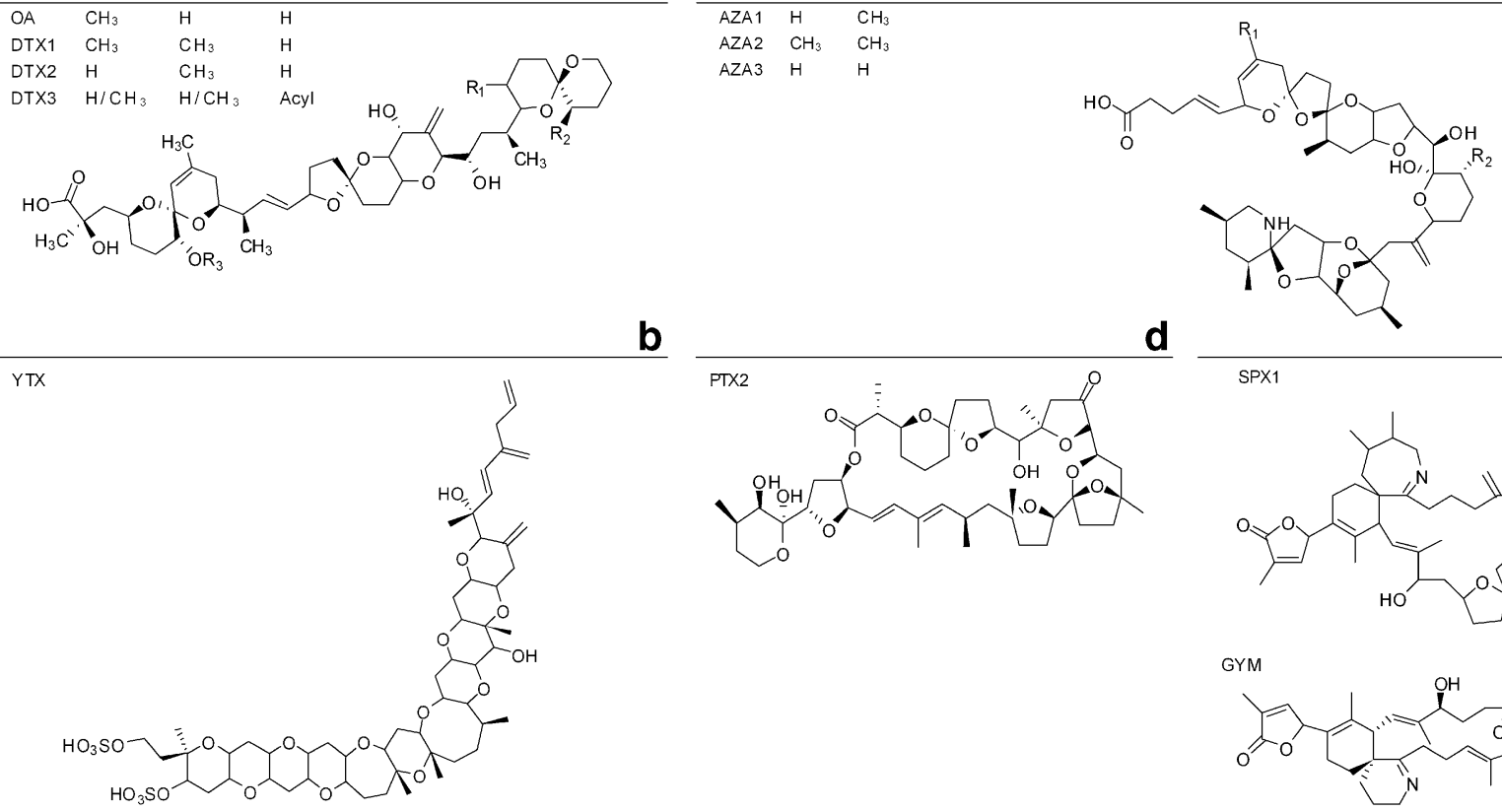

d
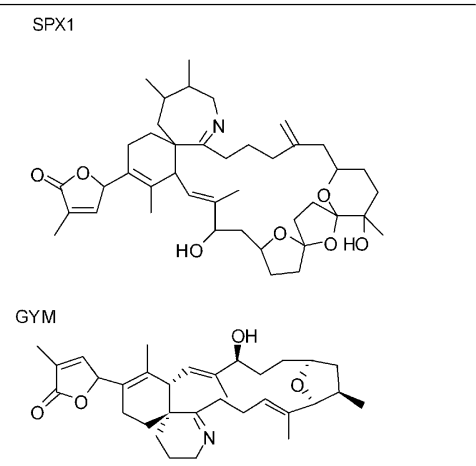

Fig. 1 Structure of a okadaic acid and dinophysistoxins 1-3, b yessotoxin, c azaspiracids 1-3, d pectenotoxin-2, e 13-desmethyl spirolide C (SPX1) and gymnodimine 
marine toxin analysis, internal standards are not available yet. Ito et al. demonstrated that standard addition can be an effective tool to eliminate matrix effects [16]. Due to the scarcity of standards, the standard addition approach is expensive and not generally feasible in routine analysis. Different techniques have been tested for the clean-up of methanolic shellfish extracts. Liquid-liquid extraction (LLE) and solid phase extraction (SPE) are the clean-up techniques most often used in the analysis of lipophilic marine biotoxins. Various organic solvents have been used for the LLE of the crude extracts [17-20]. After LLE, the organic phase is evaporated to dryness and reconstituted in methanol, acetonitrile, or acetone. The evaporation step may have a negative effect on the solubility and stability of the toxins. From a (pre-)validation round conducted within the EU BIOTOX project, it became clear that LLE did not give satisfactory results with respect to accuracy, reproducibility, and repeatability [21].

Most SPE methods are directed to the clean-up or isolation of an individual toxin or toxin group. SPE clean-up has been combined with LC-fluorescence detection (FLD) for the determination of OA and DTXs in shellfish. Puech et al. described the use of immuno-affinity cartridges with satisfactory recoveries (>55\%) [22] and Quilliam et al. used aminopropylsilica cartridges with excellent recoveries $(>95 \%)$ [23]. For the determination of OA, DTX, YTX, and PTX toxins with LC-MS, Goto et al. published a rather labor- and resource-intensive method using two parallel SPE procedures with recoveries in the range of $69-134 \%$ [24]. A $\mathrm{C}_{18}$ cartridge was used to isolate YTX and $45 \mathrm{OH}-\mathrm{YTX}$ from the crude methanolic extract, while for the isolation of OA and DTX1, LLE was applied, followed by SPE on a silica cartridge. Stobo et al. used a polymeric type SPE cartridge to isolate AZAs from crude extracts [13] and Moroney et al. used a diol-type SPE sorbent for the clean-up of AZA1-3 from shellfish extracts [25], however, the effectiveness of the clean-up has not been described in detail.

To our knowledge, there has not yet been a multi-toxin SPE method developed that accommodates the predominant lipophilic marine toxins from each of the five toxin groups. In this paper, an SPE method is presented for the isolation and clean-up of lipophilic marine toxins from all toxin groups from crude methanolic extracts. The efficiency of the SPE method in the removal of interfering matrix components resulting in a reduction or removal of ion suppression/enhancement effects was tested for three different shellfish species: mussel, scallop, and oyster. Recently, Fux et al. have shown that matrix effects can be heavily dependent on the chromatographic system used [26]. To study this in more detail, two separate LC-MS/MS methods were applied, using very different mobile phase systems $[12,27]$. For OA and PTX2, the experiments were also conducted with two electrospray ionization modes.

\section{Experimental}

Chemicals and standards

Water was deionized and passed through a Milli-Q water purification system (Millipore, Billerica, MA, USA). Formic acid (98-100\%) was purchased from Merck, Darmstadt, Germany. Ammonium formate $(>97 \%)$ was purchased from Sigma-Aldrich, Zwijndrecht, The Netherlands. Acetonitrile (HPLC supra gradient) and methanol (absolute) were purchased from Biosolve, Valkenswaard, The Netherlands. Ammonium hydroxide (25\%) was purchased from VWR International, Amsterdam, The Netherlands. OA (certified reference material (CRM)-OA-b $24.1 \pm 0.8 \mu \mathrm{g} \mathrm{mL}{ }^{-1}$ ), YTX (CRM-YTX $5.3 \pm 0.3 \mu \mathrm{g} \mathrm{mL}^{-1}$ ), AZA1 (CRM-AZA1 1.24 \pm $0.07 \mu \mathrm{g} \mathrm{mL}^{-1}$ ), PTX2 (CRM-PTX2 $\left.8.6 \pm 0.3 \mu \mathrm{g} \mathrm{mL}^{-1}\right), 13$ desmethyl spirolide C (SPX1) (CRM-SPX1 7.0 $\pm 0.4 \mu \mathrm{g}$ $\mathrm{mL}^{-1}$ ) and gymnodimine (GYM) (CRM-GYM 5.0 $\pm 0.2 \mu \mathrm{g}$ $\mathrm{mL}^{-1}$ ) were purchased from the National Research Council, Institute for Marine Biosciences (NRC CNRC), Halifax, Canada. A laboratory reference material (LRM) was prepared from mussel (Mytilus edulis) containing OA, DTX1, 2, YTX, AZA1, -2, -3 and PTX2 at the Marine Institute, Ireland. An extract in methanol with a solvent-to-sample ratio of 10 was prepared from this LRM homogenate.

Preparation of standard solutions and extracts

A stock solution containing a mixture of $320 \mathrm{ng} \mathrm{mL}^{-1} \mathrm{OA}$, $400 \mathrm{ng} \mathrm{mL}^{-1}$ YTX, $200 \mathrm{ng} \mathrm{mL}^{-1}$ AZA1 and $320 \mathrm{ng} \mathrm{mL}^{-1}$ PTX2 and a stock solution of $250 \mathrm{ng} \mathrm{mL}{ }^{-1}$ SPX1 and GYM was prepared in methanol. Blank mussel (M. edulis), scallop (Pecten maximus) and oyster (Crassostrea gigas) extracts were prepared by homogenizing $100 \mathrm{~g}$ of whole flesh with a T25 Ultra Turrax mixer at 24,000 rpm (IKA ${ }^{\circledR}$ Works Inc., Wilmington, NC, USA). $2 \mathrm{~g}$ of this shellfish homogenate was extracted in triplicate with $6 \mathrm{~mL}$ methanol. After each addition of methanol the extract was vortex mixed during $1 \mathrm{~min}$, after which the extract was centrifuged $5 \mathrm{~min}$ at $2000 \mathrm{~g}$. The methanolic extracts were combined in a $20 \mathrm{~mL}$ volumetric flask, and the volume was made up to $20 \mathrm{~mL}$ with methanol. The crude shellfish extract was filtered through a $0.2 \mu \mathrm{m}$ high temperature (HT) resistance Tuffryn membrane filter (Pall Corp., East Hills, NY, USA) prior to spiking. The crude methanolic extract was spiked at a concentration of $16 \mathrm{ng} \mathrm{mL}^{-1} \mathrm{OA}$ (equivalent to $160 \mu \mathrm{g} \mathrm{kg}^{-1} \mathrm{OA}$ ), $20 \mathrm{ng}$ $\mathrm{mL}^{-1}$ YTX (equivalent to $200 \mu \mathrm{g} \mathrm{kg}^{-1}$ YTX), $10 \mathrm{ng} \mathrm{mL}^{-1}$ AZA1 (equivalent to $100 \mu \mathrm{g} \mathrm{kg}^{-1}$ AZA1) and $16 \mathrm{ng} \mathrm{mL}^{-1}$ PTX2 (equivalent to $160 \mu \mathrm{g} \mathrm{kg}^{-1}$ PTX2). In an additional experiment the same crude blank mussel extract was spiked with $12.5 \mathrm{ng} \mathrm{mL}^{-1} \mathrm{SPX} 1$ and GYM (equivalent to $125 \mu \mathrm{g} \mathrm{kg}^{-1}$ SPX1 and GYM). 
Table 1 Multiple reaction monitoring (MRM) acquisition parameters for the selected lipophilic marine toxins

\begin{tabular}{|c|c|c|c|c|c|c|}
\hline Toxin & ESI mode & & Precursor $(m / z)$ & Product $(\mathrm{m} / \mathrm{z})$ & Cone (V) & Collision energy $(\mathrm{eV})$ \\
\hline \multirow[t]{6}{*}{ OA } & $\mathrm{ESI}^{-}$ & {$[\mathrm{M}-\mathrm{H}]^{-}$} & 803.5 & 113.1 & 60 & 50 \\
\hline & & & & 151.1 & 60 & 50 \\
\hline & & & & 255.2 & 60 & 45 \\
\hline & $\mathrm{ESI}^{+}$ & {$[\mathrm{M}+\mathrm{Na}]^{+}$} & 827.5 & 723.3 & 70 & 45 \\
\hline & & & & 791.4 & 70 & 45 \\
\hline & & & & 809.3 & 70 & 45 \\
\hline \multirow[t]{3}{*}{ YTX } & $\mathrm{ESI}^{-}$ & {$[\mathrm{M}-\mathrm{H}]^{-}$} & 1141.5 & 1061.5 & 45 & 40 \\
\hline & $\mathrm{ESI}^{-}$ & {$[\mathrm{M}-2 \mathrm{H}]^{2-}$} & 570.4 & 396.4 & 75 & 40 \\
\hline & & & & 467.4 & 75 & 40 \\
\hline \multirow[t]{3}{*}{ AZA1 } & $\mathrm{ESI}^{+}$ & {$[\mathrm{M}+\mathrm{H}]^{+}$} & 842.5 & 654.4 & 35 & 40 \\
\hline & & & & 672.4 & 35 & 40 \\
\hline & & & & 824.5 & 35 & 30 \\
\hline \multirow[t]{3}{*}{ PTX2 } & $\mathrm{ESI}^{-}$ & {$[\mathrm{M}-\mathrm{H}]^{-}$} & 857.4 & 137.2 & 90 & 45 \\
\hline & & & & 155.2 & 90 & 45 \\
\hline & & & & 179.2 & 90 & 45 \\
\hline \multirow[t]{3}{*}{ PTX2 } & $\mathrm{ESI}^{+}$ & {$\left[\mathrm{M}+\mathrm{NH}_{4}\right]^{+}$} & 876.5 & 213.1 & 40 & 30 \\
\hline & & & & 805.5 & 40 & 30 \\
\hline & & & & 823.5 & 40 & 30 \\
\hline \multirow[t]{3}{*}{ SPX1 } & $\mathrm{ESI}^{+}$ & {$[\mathrm{M}+\mathrm{H}]^{+}$} & 692.5 & 164.3 & 40 & 50 \\
\hline & & & & 444.2 & 40 & 40 \\
\hline & & & & 674.4 & 40 & 30 \\
\hline \multirow[t]{3}{*}{ GYM } & $\mathrm{ESI}^{+}$ & {$[\mathrm{M}+\mathrm{H}]^{+}$} & 508.2 & 121.4 & 50 & 45 \\
\hline & & & & 162.2 & 50 & 45 \\
\hline & & & & 490.2 & 50 & 25 \\
\hline
\end{tabular}

\section{Liquid chromatography}

An Alliance 2690 (Waters, Milford, MA, USA) HPLC system was used in combination with a Thermo Electron BDS Hypersil ${ }^{\mathrm{TM}} \mathrm{C}_{8}(50 \times 2.1 \mathrm{~mm}, 3 \mu \mathrm{m})$ column and with a Waters X-Bridge ${ }^{\mathrm{TM}} \mathrm{C}_{18}(150 \times 3 \mathrm{~mm}, 5 \mu \mathrm{m})$ column. For both columns the temperature was set at $40{ }^{\circ} \mathrm{C}$.

The Hypersil column was used under acidic conditions (pH 2.6). Mobile phase A was water and B was acetonitrile/ water $\left(95: 5 \% v v^{-1}\right)$, both containing a fixed concentration of $2 \mathrm{mM}$ ammonium formate and $50 \mathrm{mM}$ formic acid. A gradient was run at a flow rate of $0.2 \mathrm{~mL} \mathrm{~min}^{-1}$; it started with $30 \% \mathrm{~B}$, which was increased linearly to $90 \% \mathrm{~B}$ in $8 \mathrm{~min}$. The composition was kept for $2.5 \mathrm{~min}$ at $90 \% \mathrm{~B}$ and was in $0.5 \mathrm{~min}$ returned to $30 \% \mathrm{~B}$. An equilibration time of 4 min was allowed before the next injection.

The X-Bridge $\mathrm{C}^{\mathrm{TM}}$ column was used under alkaline conditions ( $\mathrm{pH} 11)$ with water as mobile phase $\mathrm{A}$ and acetonitrile/water (90:10\%v $\left.v v^{-1}\right)$ as mobile phase B. Both mobile phases contained $6.7 \mathrm{mM}$ ammonium hydroxide. A gradient was run at a flow rate of $0.4 \mathrm{~mL} \mathrm{~min}^{-1}$; the gradient started with $10 \% \mathrm{~B}$, which was after one min increased linearly to $90 \% \mathrm{~B}$ in $9 \mathrm{~min}$. The composition was kept at $90 \%$ B for 3 min and was in 2 min returned to $10 \%$
B. An equilibration time of 4 min was allowed before the next injection. For both the acidic and alkaline LC method, the vial compartment of the autosampler was kept at $10{ }^{\circ} \mathrm{C}$ and a $10-\mu \mathrm{L}$ injection volume was used.

Mass spectrometry

Mass spectrometry was performed using a Micromass Quattro Ultima tandem mass spectrometer (Waters-Micromass, Manchester, UK) equipped with an electrospray ionization interface (ESI). The mass spectrometer was operated in the negative ESI (ESI ${ }^{-}$) and the positive ESI $\left(\mathrm{ESI}^{+}\right)$mode, with a capillary voltage of $2.8 \mathrm{kV}$, a desolvation temperature of $350{ }^{\circ} \mathrm{C}$ at a nitrogen gas flow rate of $600 \mathrm{~L} \mathrm{~h}^{-1}$, a source temperature of $120{ }^{\circ} \mathrm{C}$, and a cone gas flow rate of $100 \mathrm{~L} \mathrm{~h}^{-1}$. Argon was used as collision-induced dissociation (CID) gas at a pressure of $2.3 \times 10^{-3}$ mbar. The cone voltage and collision energy were optimized by direct infusion experiments under acidic and alkaline conditions (Table 1). For both LC gradients negative and positive ionization were applied in separate runs. OA and PTX2 were analyzed in both the ESI $^{-}$and $\mathrm{ESI}^{+}$mode while YTX was analyzed only in the $\mathrm{ESI}^{-}$mode and AZA1, SPX1, and GYM only in the $\mathrm{ESI}^{+}$mode, 
respectively. For the acidic and alkaline LC method a solvent delay of respectively 2 and 3 min was used to reduce contamination of the MS interface.

Solid phase extraction

\section{Automated SPE system (Symbiosis Pharma)}

Development of the SPE procedure was performed using an array of cartridges and sorbents from different manufacturers. Due to a very limited availability of standards, optimization of the SPE method was carried out using the LRM extract. SPE sorbent screening was performed with an automated SPE system, the Symbiosis Pharma (Spark Holland, Emmen, The Netherlands). The Symbiosis Pharma consists of a temperature-controlled stacker, a temperature-controlled autosampler (Reliance), a highpressure dispenser (HPD single), a high-pressure mix with a solvent-selection manifold, a gradient pump set, and an automatic cartridge exchanger (ACE). With the Symbiosis Pharma, the following sorbents were tested: Cyano, $\mathrm{C}_{2}, \mathrm{C}_{8}$, $\mathrm{C}_{8}$ endcapped $\left(\mathrm{C}_{8} \mathrm{ec}\right), \mathrm{C}_{18}, \mathrm{C}_{18}$ high definition $\left(\mathrm{C}_{18} \mathrm{HD}\right)$, general purpose resin (GP) and strongly hydrophobic resin (SH), all cartridges containing $12.5 \mathrm{mg}$ sorbent from Spark Holland, Emmen, The Netherlands, and weak cationexchange (WCX), strong cation-exchange (MCX), weak anion-exchange (WAX) and strong anion-exchange (MAX) cartridges containing $2.5 \mathrm{mg}$ sorbent from Waters, Ettenleur, The Netherlands (Table 2).

All cartridges were conditioned with $1 \mathrm{~mL}$ methanol and equilibrated with $1 \mathrm{~mL} 30 \% v v^{-1}$ methanol/water. The crude methanolic shellfish extract was diluted with water to an organic strength of $30 \% v v^{-1}$ methanol/water and $25 \mu \mathrm{L}$ of the diluted extract was automatically transferred to the top of the cartridge. The Cyano, $\mathrm{C}_{2}$, $\mathrm{C}_{8}, \mathrm{C}_{8}$ ec, $\mathrm{C}_{18}, \mathrm{C}_{18} \mathrm{HD}$, GP, and $\mathrm{SH}$ cartridge were washed with $1 \mathrm{~mL} 20 \% v v^{-1}$ methanol/water and subsequently eluted with $500 \mu \mathrm{L}$ methanol/water containing $1 \% v v^{-1}$ ammonium hydroxide (25\%). The ionexchange cartridges (WCX, MCX, WAX, and MAX) were washed with $1 \mathrm{ml} 5 \% v v^{-1}$ ammonium hydroxide (25\%) in water, $30 \% v v^{-1}$ methanol/water or $2 \% v v^{-1}$ formic acid in water. Elution was carried out with $500 \mu \mathrm{L} 5 \%$ $v v^{-1}$ ammonium hydroxide (25\%) in methanol, methanol or $2 \% v v^{-1}$ formic acid in methanol. The Symbiosis SPE extracts were analyzed by LC-MS/MS using the alkaline LC gradient.

\section{Initially selected SPE protocol}

In order to optimize the off-line SPE, two different cartridges containing polymeric sorbents were used: $60 \mathrm{mg} 3 \mathrm{~mL}$ Oasis ${ }^{\circledR}$ HLB (Waters, Etten-leur, The Nether- lands) and $60 \mathrm{mg} 3 \mathrm{~mL}$ Strata ${ }^{\mathrm{TM}}-\mathrm{X}$ (Phenomenex, Torrance, CA, USA). The retention capacity of both cartridges was investigated by application of LRM extract diluted before application with $60 \%$ water. The cartridges were subsequently washed with $50 \% v v^{-1}$ methanol and eluted with methanol. The wash and elution solvents and volumes were optimized during the method development stage for the cartridge with the best retention capacity. Furthermore, break-through, wash losses, and recoveries, based on the mass spectrometric analysis of the toxins present in the LRM material, before and after SPE clean-up were determined. Based on the results obtained the final SPE protocol was defined.

\section{Final SPE protocol}

After further optimization (see "Optimization of the SPE clean-up protocol" section) a $30 \mathrm{mg} 1 \mathrm{~mL}$ Strata $^{\mathrm{TM}}-\mathrm{X}$ cartridge was selected. It was activated with $1 \mathrm{~mL}$ of methanol. Prior to application of the sample, the cartridge was equilibrated using $1 \mathrm{~mL} 30 \% v v^{-1}$ methanol. Crude methanolic shellfish extract $(1.2 \mathrm{~mL})$ was diluted with $2.8 \mathrm{~mL}$ water and applied on the cartridge. The cartridge was washed with $1 \mathrm{~mL} 20 \% v v^{-1}$ methanol in order to remove polar compounds. Finally the toxins were eluted from the cartridge using $1.2 \mathrm{~mL}$ methanol containing $0.3 \%$ $v v^{-1}$ ammonium hydroxide. The purified extracts were transferred to an HPLC vial and analyzed by LC-MS/MS. Various parameters were investigated (Fig. 2). The recovery of the SPE clean-up step was determined by comparing the MS response of individual toxins spiked to the crude extract pre-SPE with the same toxins spiked to the purified extract post SPE. Secondly, the matrix effect observed for each toxin in the crude extract was determined for both LC gradients by comparing the toxins spiked to crude extract with the toxins spiked to methanol. In the same way, the matrix effects observed in the purified extracts, obtained after SPE, were determined by comparing the purified extract with the toxins spiked to methanol. Finally, the apparent recovery, defined as the combination of the (reduced) matrix effect and the recovery of the SPE was established by comparing the pre-SPE toxinspiked extracts with the toxins spiked to methanol. All experiments were repeated five times for each matrix, the results were based on the total area of three transitions, except for YTX where under acidic conditions one transition was used (Table 1). At low $\mathrm{pH}$, the predominant precursor ion was the single charged molecule at $\mathrm{m} / \mathrm{z}$ 1,141.5 $[\mathrm{M}-\mathrm{H}]^{-}$, while at high $\mathrm{pH}$, the predominant precursor was the doubly charged molecule $[\mathrm{M}-2 \mathrm{H}]^{2-}$, at $m / z$ 570.4. Therefore, the $[\mathrm{M}-\mathrm{H}]^{-}$ion was used with the acidic LC conditions and the with the $[\mathrm{M}-2 \mathrm{H}]^{2-}$ with the alkaline LC conditions. 
Table 2 Sorbents tested for clean-up of marine lipophilic toxins

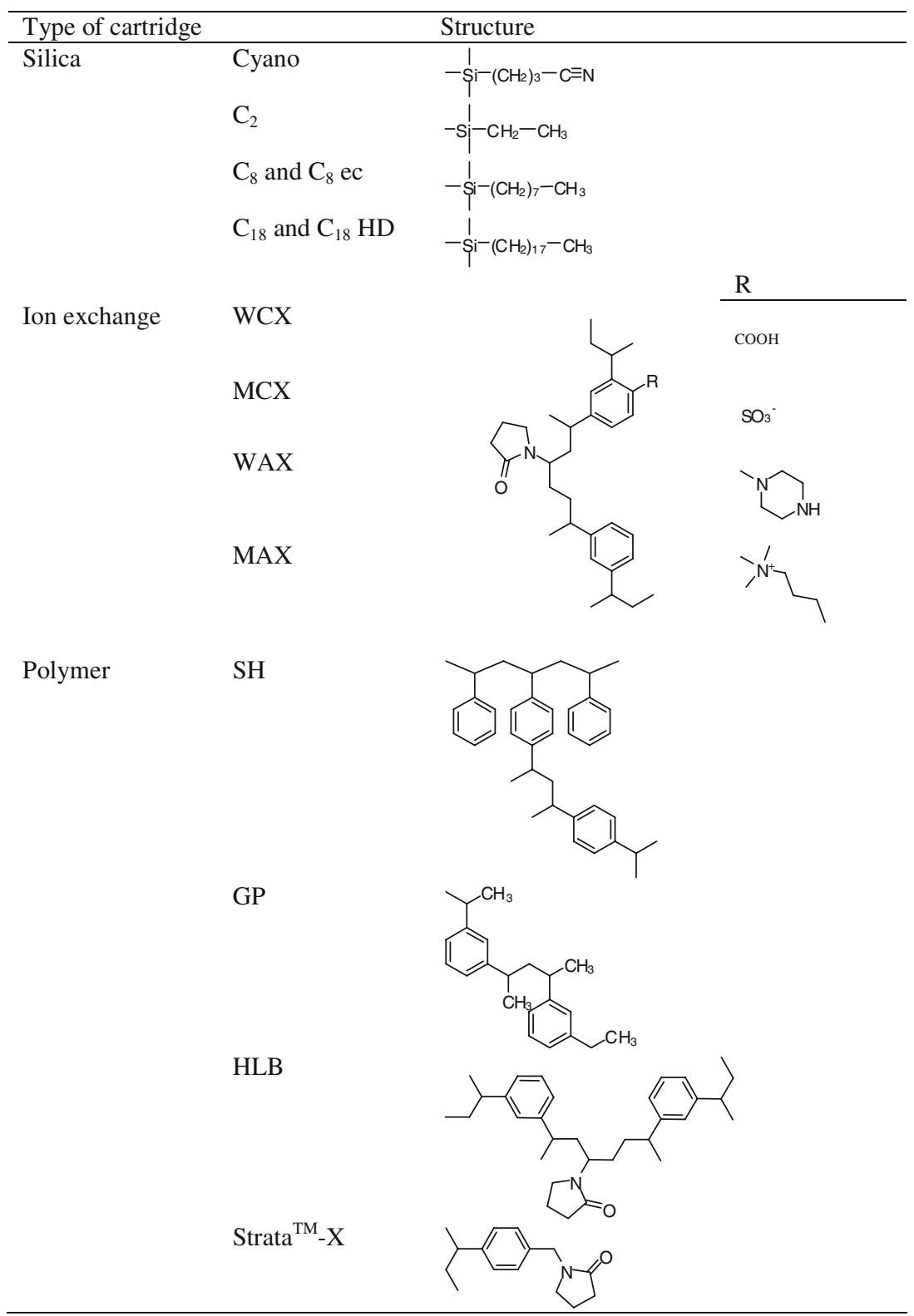

\section{Results and discussion}

Initial method development

The first step of the SPE method development focused on finding an appropriate sorbent which retained the various toxin groups. With the Symbiosis Pharma system, a rapid sorbent screening of 12 different sorbents ranging from very polar to strongly hydrophobic was performed (see Table 2 for the chemistry of the sorbents). On most cartridges, retention may be expected based on the lipophilic character of the toxins tested. Additional retention due to the presence of ionizable functional groups may play an important role when ion-exchange cartridges are used.

Based on the chemistry of the ion-exchange sorbents, a prediction could be made for the interaction of the various toxins with these sorbents, indicating the difficulties to be expected in finding an appropriate sorbent which will retain all lipophilic marine toxins. To study the retention of the toxins on the various ion-exchange sorbents, the cartridges were washed and eluted with alkaline, neutral, and acidic solutions. All wash and elution combinations were tested per ion-exchange cartridge. In this way, the cartridges were also used in their non-ideal or even opposite polarity of wash and elution conditions. OA, which contains a 
Fig. 2 Flowchart of the investigated parameters of the SPE clean-up

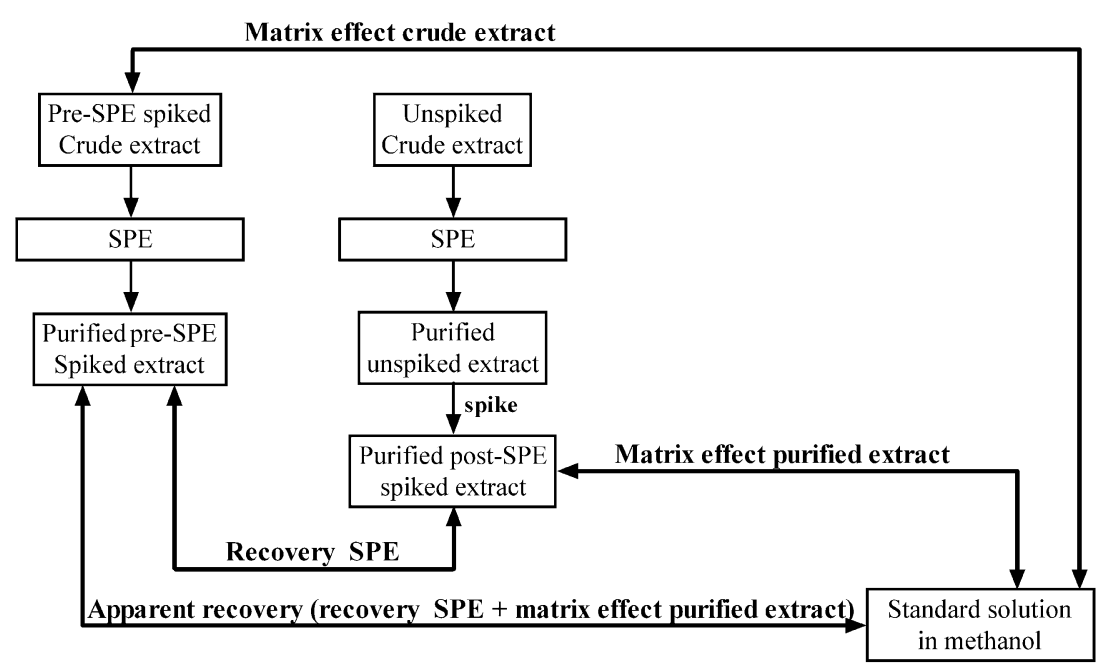

carboxylic acid group, was very well retained on the MAX cartridge as expected; but also the WAX cartridge (specific for strong acids) yielded a high recovery under most of the applied wash and elution conditions, with the exception of the alkaline wash and acidic elution $(<25 \%$; Fig. 3). YTX contains two sulfonic acid groups and should be retained on a WAX cartridge. Good recoveries on the WAX cartridge were obtained for YTX, when a neutral or acidic wash was applied in combination with alkaline elution (Fig. 3). However, the recovery for YTX was poor on the MAX, WCX, and MCX cartridge regardless of the conditions applied. AZA1 is an amphoteric compound containing a carboxylic acid as well as an amino group, and could be retained on the MAX as well as on the MCX cartridge. The
MAX cartridge gave good recoveries for AZA1 with an alkaline wash followed by acidic elution and with a neutral wash and basic elution. Furthermore, reasonable recoveries were obtained for AZA1 on the MCX and WCX cartridge with an acidic or neutral wash and neutral or alkaline elution (Fig. 3). SPX1 and GYM contain an imine group which should be retained best on an MCX cartridge. However, SPX1 was also well retained on the WCX cartridge under most conditions (Fig. 3). PTX2, a neutral compound, does not contain any specific functional groups. For this reason, it is difficult to predict its behavior on the different cartridges. In practice, PTX2 had some retention on all cartridge types. The best recoveries were obtained on the MAX and WCX cartridges under acidic wash con-
Fig. 3 Sorbent screening of different ion-exchange cartridges using the Symbiosis Pharma automated SPE system. Highest signal intensity per individual toxin set at $100 \%$ $(n=2)$

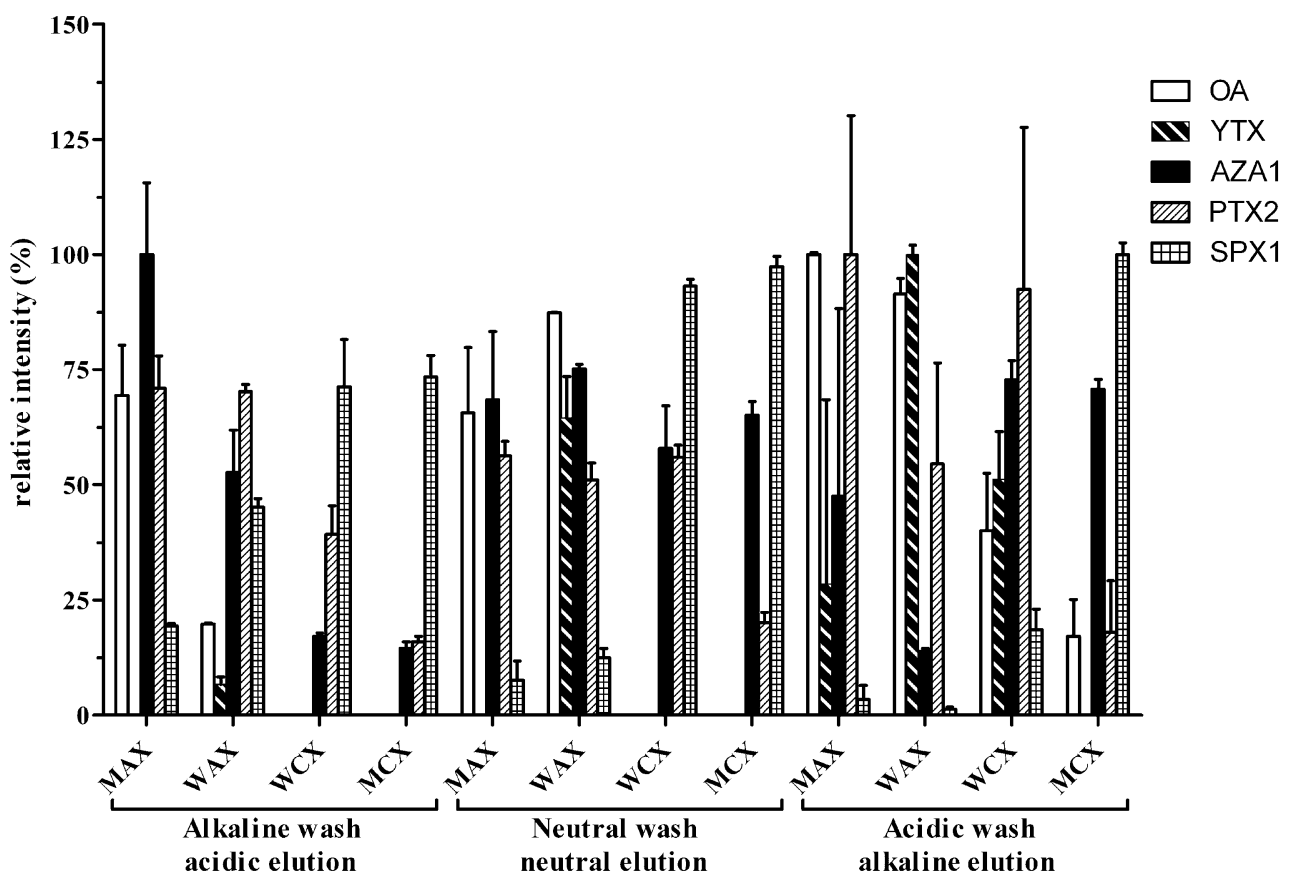


ditions. Reasonable recoveries were obtained on the MAX and WAX cartridges using an alkaline wash and acidic elution.

Figure 3 shows that only in two instances (MAX and WAX with acidic wash and alkaline elution) two out of five toxins were retained with high efficiency ( $>90 \%)$. Only on one occasion (WAX cartridge with a neutral wash and neutral elution step), four out of five toxin groups could be recovered with more than $50 \%$ yield. It is evident that it will be very difficult to find an ion-exchange cartridge and the appropriate wash and elution conditions at which for all five toxin groups good recoveries are obtained.

With respect to the silica-based sorbents that were tested with the Symbiosis Pharma system, OA gave good recoveries on all the cartridges that were investigated, with the exception of the CN cartridge (Fig. 4). For YTX, good recoveries were obtained with the $\mathrm{C}_{18} \mathrm{HD}$ and $\mathrm{GP}$ cartridge, while AZA1 showed good recoveries on all the cartridges except on the $\mathrm{SH}$ cartridge. The recovery of PTX2 was good on all cartridges with the exception of the $\mathrm{CN}$ cartridge. From the data shown in Fig. 4, it is clear that the $\mathrm{C}_{18} \mathrm{HD}$ and GP cartridges showed overall the best recoveries of the five toxin groups.

In conclusion, for the ion-exchange and silica-based cartridges and for each toxin different optimum conditions and different optimal sorbents were obtained. Especially for YTX, it was difficult to find suitable conditions that would match with the other toxins. As none of the cartridges dealt with above is capable to retain all five toxin groups, the focus changed towards general purpose polymeric cartridges. These polymeric cartridges can be applied for a broad range of compounds. Two different brands of polymeric sorbents were selected for further investigation,

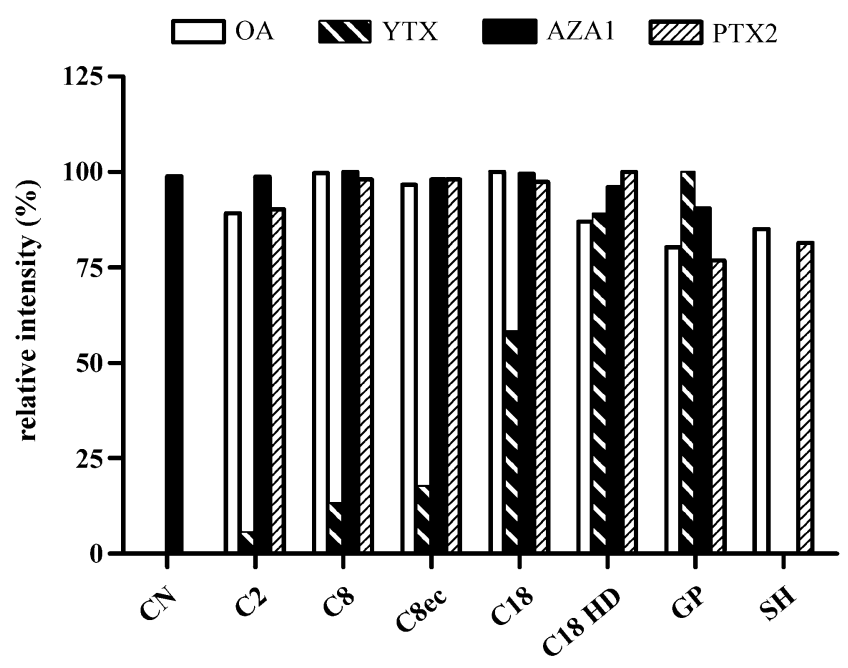

Fig. 4 Sorbent screening using the Symbiosis Pharma automated SPE system. Highest signal intensity per individual toxin set at $100 \%$. Wash with $20 \% v v^{-1}$ methanol/water elution with $1 \% v v^{-1} \mathrm{NH}_{4} \mathrm{OH}$ in methanol
Oasis $^{\circledR}$ hydrophilic lipophilic balance (HLB) and Strata ${ }^{\text {TM }}$ $\mathrm{X}$. Because the Strata ${ }^{\mathrm{TM}}-\mathrm{X}$ cartridge was not available for the Symbiosis Pharma system, further optimization experiments were performed off-line. With polymeric cartridges such as Oasis $^{\circledR}$ HLB and Strata ${ }^{\mathrm{TM}}$-X retention of compounds is based on their polar and lipophilic interactions.

\section{Optimization of the SPE clean-up protocol}

In comparison with the previous tested sorbents (ionexchange and silica) the polymeric cartridges are capable to retain all the lipophilic marine toxin groups. From Fig. 5 it can be seen that OA, DTX1, DTX2, and YTX retained $20-50 \%$ better on the Strata ${ }^{\mathrm{TM}}-\mathrm{X}$ than on the Oasis ${ }^{\circledR}$ HLB cartridge during the application and wash step. AZA1, -2, 3 , and PTX2 were retained $5-10 \%$ better on the Oasis ${ }^{\circledR}$ HLB cartridge. Overall, Strata ${ }^{\mathrm{TM}}-\mathrm{X}$ performed better. Therefore, the Strata ${ }^{\mathrm{TM}}-\mathrm{X}$ cartridge was used for further optimization experiments. Volume and organic solvent strength of the applied crude extract, wash step, and elution step were optimized.

\section{Solvent strength of crude extract}

The volume and organic solvent strength of the crude shellfish LRM extract tolerated during application on the Strata ${ }^{\mathrm{TM}}-\mathrm{X}$ cartridge was investigated. No break-through was observed when the crude methanol extracts $(2 \mathrm{~mL})$ were diluted to $30 \% v v^{-1}$ methanol in water prior to application to the SPE cartridge. At a higher percentage, methanol $\left(40 \%, 50 \%, 60 \% v v^{-1}\right.$ methanol in water) breakthrough of OA, DTX1, DTX2, and YTX was observed. Increasing volumes of crude sample extract (up to $6 \mathrm{~mL}$ diluted to $30 \% v v^{-1}$ methanol by mixing with $14 \mathrm{~mL}$ water) were applied to the $60 \mathrm{mg}$ cartridge. In none of the extracts was break-through of any of the toxins observed. Thus, if necessary, a concentration step can be incorporated into the extraction protocol.

\section{Wash step}

The organic solvent strength of the wash step $(3 \mathrm{~mL})$ was optimized by using $0-70 \% v v^{-1}$ methanol/water mixtures with increments of $10 \%$. OA, DTX1, DTX2, and YTX started to elute (less than 3\%) when wash solutions were used with more than $30 \%$ methanol. AZAs were retained on the cartridge with up to $50 \%$ methanol and PTX2 did not elute even with $70 \%$ methanol. A wash step of $20 \% v v^{-1}$ methanol/water was incorporated to avoid losses during washing.

Next, the effect of using acidic, neutral, or alkaline $20 \%$ $v v^{-1}$ methanol/water as wash solvent was investigated. The acidic wash solvent contained $1 \% v v^{-1}$ formic acid and the 


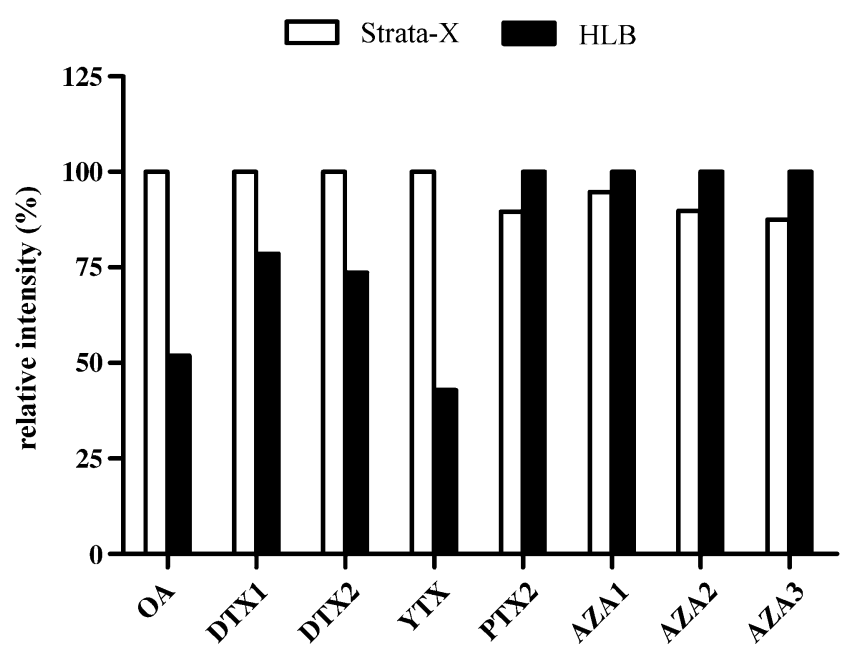

Fig. 5 Relative intensity of selected toxins on two different sorbents with the preliminary SPE protocol. Highest intensity per individual toxin is set at $100 \%$. Wash with $50 \% v v^{-1}$ methanol and elution with methanol

alkaline wash solvent $1 \% v v^{-1}$ ammonium solution. As no significant differences in recovery of the toxins were obtained between the various wash solvents, a neutral wash step of $20 \% v v^{-1}$ methanol/water was incorporated in the final method.

\section{Elution step}

Elution was performed with $2 \mathrm{~mL}$ methanol. To estimate the amount of remaining toxins on the cartridge a second elution step with $2 \mathrm{~mL}$ methanol, collected in a second vial, was incorporated. The first elution resulted in an almost complete recovery $(>90 \%)$ of OA, DTX1, DTX2, AZA1, AZA2, AZA3, and PTX2 but for YTX, the recovery was somewhat lower (60-70\%). Around $10-20 \%$ of YTX was eluted in the second step. The recovery of YTX correlated with the $\mathrm{pH}$ of the wash step used during clean-up. With an alkaline wash step, the recovery of YTX was higher (80$90 \%$ ), while with an acidic wash step, it was lower (50$60 \%$ ). By adding $0.3 \% v v^{-1}$ ammonia solution to the elution solvent, the recovery could be increased to around $90 \%$ for YTX without affecting the recoveries of the other toxins. Using higher concentrations of ammonia did not further improve recoveries.

The stability of the toxins under alkaline conditions in the presence of ammonia has been investigated previously [12]. No degradation of any of the toxins was observed even at concentrations of $12.5 \% v v^{-1}$ ammonia in water.

\section{Performance of the optimized protocol}

All optimization experiments were conducted with $60 \mathrm{mg}$ Strata $^{\mathrm{TM}}-\mathrm{X}$ cartridges. Although this may be a very practical size to be used in routine monitoring of shellfish samples it was decided to downscale the procedure to $30 \mathrm{mg}$ cartridges in order to save valuable toxin standards.

To study the efficacy of the optimized SPE protocol with respect to recovery and matrix effects, methanolic extracts with a solvent-to-sample ratio of 10, from blank mussels, scallops, and oysters were spiked with OA, YTX, AZA1, and PTX2. In a second experiment, SPX1 and GYM were spiked to a blank mussel extract to check if the developed method could also be applied for these toxins as well. Toxin concentrations were chosen such that they were at $\left(16 \mathrm{ng} \mathrm{mL}^{-1} \mathrm{OA}\right.$ and PTX2) or somewhat below $\left(20 \mathrm{ng} \mathrm{mL}^{-1}\right.$ YTX and $10 \mathrm{ng} \mathrm{mL}^{-1}$ AZA1) the current permitted level in EU legislation [10]. For SPX1 and GYM, there is currently no legislation established. These toxins were added to the mussel extract at a concentration of $12.5 \mathrm{ng} \mathrm{mL}^{-1}$.

It was anticipated that the chromatographic conditions used prior to MS detection can be of importance to the observed matrix effects [26]. Changing the $\mathrm{pH}$ of the mobile phase may lead to an altered separation of toxins and matrix components. To investigate the effect of chromatographic separation, two different established HPLC methods were used [12, 28], one using acidic conditions and the other one alkaline conditions. As was shown before, the elution profile of the toxins is quite different under these conditions [12].

The ion ratios of the various transitions were reproducible with RSDs lower than $15 \%$ ( $n=70$, data not shown). The only exception was PTX2 analyzed in the $\mathrm{ESI}^{-}$mode in combination with the acidic LC method. Due to an eightfold-lower sensitivity, compared to $\mathrm{ESI}^{+}$, an RSD of around $25 \%$ was obtained.

\section{Recovery of the SPE method}

The SPE clean-up procedure using Strata ${ }^{\mathrm{TM}}-\mathrm{X}$ cartridges worked well for OA, YTX, AZA1, PTX2, SPX1, and GYM yielding good to excellent recoveries (Tables 3, 4, and 5). The average recovery of all toxins and matrices combined was good, $90.0 \pm 6.0 \%$ as determined with the alkaline LC gradient, and $92.6 \pm 6.9 \%$ with the acidic LC gradient. For individual toxins the recovery varied between $74.6 \pm 2.9 \%$ for YTX in oyster extract (as determined by the alkaline LC gradient method) and $102.9 \pm 10.7 \%$ for OA in oyster extract (measured in $\mathrm{ESI}^{-}$with the acidic gradient). In general, the relative standard deviations (RSD) obtained with the alkaline method (max. 12.5\% for GYM) were better compared to those of the acidic method (max. $22.3 \%$ for AZA1). Ideally, the recoveries calculated with both methods should not be significantly different, because the recovery of the SPE should not be influenced by the chromatographic system used. Indeed, most of the recov- 
Table 3 Performance parameters of the optimized SPE protocol for mussel extracts

\begin{tabular}{|c|c|c|c|c|c|c|c|c|c|c|}
\hline \multirow[t]{3}{*}{ Toxin } & \multirow[t]{3}{*}{ Ionization } & \multirow[t]{3}{*}{ LC conditions } & \multirow{2}{*}{\multicolumn{2}{|c|}{ Recovery SPE (\%) }} & \multicolumn{4}{|c|}{ Percentage matrix effects } & \multicolumn{2}{|c|}{ Apparent recovery $(\%)$} \\
\hline & & & & & \multicolumn{2}{|l|}{ Crude $(\%)$} & \multicolumn{2}{|c|}{ After SPE (\%) } & \multirow[b]{2}{*}{$\operatorname{Avg}(n=5)$} & \multirow[b]{2}{*}{ RSD } \\
\hline & & & $\operatorname{Avg}(n=5)$ & RSD & $\operatorname{Avg}(n=5)$ & RSD & $\operatorname{Avg}(n=5)$ & RSD & & \\
\hline \multirow[t]{2}{*}{$\mathrm{OA}$} & \multirow[t]{2}{*}{$\mathrm{ESI}^{-}$} & Alkaline & 90.0 & 6.4 & 99.3 & 3.8 & 104.9 & 4.4 & 94.5 & 6.0 \\
\hline & & Acidic & 102.5 & 4.7 & 104.7 & 8.1 & 106.9 & 7.5 & 109.5 & 8.4 \\
\hline \multirow[t]{2}{*}{$\mathrm{OA}$} & \multirow[t]{2}{*}{$\mathrm{ESI}^{+}$} & Alkaline & 93.6 & 4.8 & 23.8 & 8.4 & $61.3^{\mathrm{a}}$ & 8.2 & $57.3^{\mathrm{a}}$ & 7.5 \\
\hline & & Acidic & 92.5 & 10.1 & 61.1 & 12.8 & $119.2^{\mathrm{a}}$ & 14.1 & $110.3^{\mathrm{a}}$ & 16.0 \\
\hline \multirow[t]{2}{*}{ YTX } & \multirow[t]{2}{*}{$\mathrm{ESI}^{-}$} & Alkaline & 90.0 & 4.7 & 95.4 & 4.6 & 109.9 & 5.0 & 99.0 & 5.3 \\
\hline & & Acidic & 93.2 & 8.3 & 124.9 & 14.5 & 122.4 & 19.4 & 114.0 & 20.7 \\
\hline \multirow[t]{2}{*}{ AZA1 } & \multirow[t]{2}{*}{ ESI+ } & Alkaline & 88.6 & 3.5 & 88.1 & 5.7 & $98.2^{\mathrm{a}}$ & 6.5 & 86.9 & 5.8 \\
\hline & & Acidic & 85.5 & 22.3 & 84.3 & 10.3 & $105.6^{\mathrm{a}}$ & 9.6 & 90.2 & 23.3 \\
\hline \multirow[t]{2}{*}{ PTX2 } & \multirow[t]{2}{*}{$\mathrm{ESI}^{-}$} & Alkaline & 89.3 & 5.3 & 64.7 & 8.0 & $101.1^{\mathrm{a}}$ & 5.9 & $90.3^{\mathrm{a}}$ & 5.6 \\
\hline & & Acidic & 95.5 & 17.4 & 105.9 & 16.0 & 106.8 & 19.4 & 102.0 & 20.2 \\
\hline \multirow[t]{2}{*}{ PTX2 } & \multirow[t]{2}{*}{ ESI+ } & Alkaline & 90.0 & 3.9 & 56.5 & 5.3 & $86.7^{\mathrm{a}}$ & 5.3 & $78.0^{\mathrm{a}}$ & 5.5 \\
\hline & & Acidic & 89.0 & 8.4 & 139.5 & 7.7 & 128.1 & 11.4 & $114.0^{\mathrm{a}}$ & 13.0 \\
\hline \multirow[t]{2}{*}{ SPX1 } & \multirow[t]{2}{*}{ ESI+ } & Alkaline & 100.7 & 11.6 & 89.4 & 5.0 & 95.6 & 10.3 & 96.2 & 7.8 \\
\hline & & Acidic & 96.3 & 13.4 & 95.7 & 6.0 & $64.9^{\mathrm{b}}$ & 11.6 & $62.6^{\mathrm{b}}$ & 8.8 \\
\hline \multirow[t]{2}{*}{ GYM } & \multirow[t]{2}{*}{ ESI+ } & Alkaline & 96.9 & 12.5 & 81.1 & 6.4 & $95.8^{\mathrm{a}}$ & 11.3 & $92.9^{\mathrm{a}}$ & 9.0 \\
\hline & & Acidic & 89.0 & 9.8 & 92.5 & 4.5 & $70.3^{\mathrm{b}}$ & 9.4 & $62.5^{\mathrm{b}}$ & 5.4 \\
\hline
\end{tabular}

Numbers given in italics: when RSD above $15 \%$ or when recovery, crude, after SPE or apparent recovery are below $85 \%$ or above $115 \%$

${ }^{a}$ Significantly improved compared to crude extract $(p \leq 0.05)$

${ }^{\mathrm{b}}$ Significant deterioration compared to the crude extract $(p \leq 0.05)$

eries obtained were not significantly different $(p \leq 0.05)$

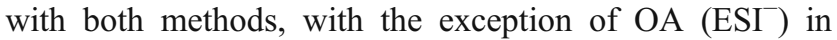
mussel and in oyster and YTX in oyster. For OA, no explanation can be given for the differences in the recovery obtained. For YTX, the differences in recovery can be explained by the peak shape of YTX that was rather poor under acidic conditions, which hampered an accurate integration of ion signals (Fig. 6).

Table 4 Performance parameters of the optimized SPE protocol for scallop extracts

\begin{tabular}{|c|c|c|c|c|c|c|c|c|c|c|}
\hline \multirow[t]{3}{*}{ Toxin } & \multirow[t]{3}{*}{ Ionization } & \multirow[t]{3}{*}{ LC conditions } & \multirow{2}{*}{\multicolumn{2}{|c|}{ Recovery (\%) }} & \multicolumn{4}{|c|}{ Percentage matrix effects } & \multicolumn{2}{|c|}{ Apparent recovery $(\%)$} \\
\hline & & & & & \multicolumn{2}{|l|}{ Crude (\%) } & \multicolumn{2}{|c|}{ After SPE (\%) } & & \\
\hline & & & Avg $(n=5)$ & RSD & $\operatorname{Avg}(n=5)$ & RSD & $\operatorname{Avg}(n=5)$ & RSD & $\operatorname{Avg}(n=5)$ & RSD \\
\hline \multirow[t]{2}{*}{$\mathrm{OA}$} & \multirow[t]{2}{*}{$\mathrm{ESI}^{-}$} & Alkaline & 93.6 & 3.2 & 98.9 & 4.7 & 104.4 & 5.1 & 97.8 & 4.3 \\
\hline & & Acidic & 102.3 & 9.7 & 128.8 & 10.6 & $85.5^{\mathrm{a}}$ & 12.5 & $87.5^{\mathrm{a}}$ & 11.2 \\
\hline \multirow[t]{2}{*}{ OA } & \multirow[t]{2}{*}{ ESI+ } & Alkaline & 85.8 & 4.2 & 17.6 & 19.3 & $101.2^{\mathrm{a}}$ & 14.3 & $86.9^{\mathrm{a}}$ & 14.6 \\
\hline & & Acidic & 91.9 & 11.3 & 203.1 & 19.9 & $115.4^{\mathrm{a}}$ & 19.9 & $106.1^{\mathrm{a}}$ & 19.9 \\
\hline \multirow[t]{2}{*}{ YTX } & \multirow[t]{2}{*}{$\mathrm{ESI}^{-}$} & Alkaline & 88.5 & 3.6 & 98.2 & 6.0 & 113.5 & 6.2 & $100.4^{\mathrm{a}}$ & 5.5 \\
\hline & & Acidic & 94.8 & 10.2 & 105.9 & 11.8 & 99.0 & 13.0 & 93.9 & 13.0 \\
\hline \multirow[t]{2}{*}{ AZA1 } & \multirow[t]{2}{*}{ ESI+ } & Alkaline & 86.4 & 3.0 & 89.0 & 4.9 & $102.8^{\mathrm{a}}$ & 4.4 & 88.8 & 5.0 \\
\hline & & Acidic & 86.4 & 7.2 & 59.1 & 35.9 & 80.0 & 14.5 & 69.1 & 13.9 \\
\hline \multirow[t]{2}{*}{ PTX2 } & \multirow[t]{2}{*}{$\mathrm{ESI}^{-}$} & Alkaline & 89.9 & 4.7 & 56.7 & 7.9 & $88.7^{\mathrm{a}}$ & 6.7 & $79.7^{\mathrm{a}}$ & 7.0 \\
\hline & & Acidic & 94.2 & 17.2 & 115.6 & 17.6 & 90.5 & 18.0 & 85.3 & 12.2 \\
\hline \multirow[t]{2}{*}{ PTX2 } & \multirow[t]{2}{*}{$\mathrm{ESI}+$} & Alkaline & 90.1 & 2.8 & 71.1 & 5.1 & $94.1^{\mathrm{a}}$ & 4.9 & $84.8^{\mathrm{a}}$ & 5.0 \\
\hline & & Acidic & 88.5 & 8.7 & 128.4 & 9.9 & 111.4 & 10.2 & $98.6^{\mathrm{a}}$ & 9.3 \\
\hline
\end{tabular}

Numbers given in italics: when RSD above $15 \%$ or when recovery, crude, after SPE or apparent recovery are below $85 \%$ or above $115 \%$

${ }^{a}$ Significantly improved compared to crude extract $(p \leq 0.05)$ 
Table 5 Performance parameters of the optimized SPE protocol for oyster extracts

\begin{tabular}{|c|c|c|c|c|c|c|c|c|c|c|}
\hline \multirow[t]{3}{*}{ Toxin } & \multirow[t]{3}{*}{ Ionization } & \multirow[t]{3}{*}{ LC conditions } & \multirow{2}{*}{\multicolumn{2}{|c|}{ Recovery (\%) }} & \multicolumn{4}{|c|}{ Percentage matrix effects } & \multirow{2}{*}{\multicolumn{2}{|c|}{ Apparent Recovery (\%) }} \\
\hline & & & & & \multicolumn{2}{|l|}{ Crude $(\%)$} & \multicolumn{2}{|c|}{ After SPE (\%) } & & \\
\hline & & & $\operatorname{Avg}(n=5)$ & RSD & $\operatorname{Avg}(n=5)$ & RSD & $\operatorname{Avg}(n=5)$ & RSD & $\operatorname{Avg}(n=5)$ & RSD \\
\hline \multirow[t]{2}{*}{ OA } & \multirow[t]{2}{*}{$\mathrm{ESI}^{-}$} & Alkaline & 85.8 & 5.0 & 79.6 & 7.0 & $93.4^{\mathrm{a}}$ & 7.1 & 80.1 & 7.0 \\
\hline & & Acidic & 102.9 & 10.7 & 123.6 & 9.5 & $90.9^{\mathrm{a}}$ & 13.6 & $93.6^{\mathrm{a}}$ & 15.3 \\
\hline \multirow[t]{2}{*}{ OA } & \multirow[t]{2}{*}{ ESI+ } & Alkaline & 94.4 & 5.2 & 19.0 & 9.5 & $44.9^{\mathrm{a}}$ & 10.0 & $42.4^{\mathrm{a}}$ & 9.7 \\
\hline & & Acidic & 94.1 & 6.7 & 140.5 & 22.9 & 117.7 & 22.8 & 110.7 & 22.3 \\
\hline \multirow[t]{2}{*}{ YTX } & \multirow[t]{2}{*}{$\mathrm{ESI}^{-}$} & Alkaline & 74.6 & 2.9 & 80.3 & 4.9 & $103.9^{\mathrm{a}}$ & 5.2 & 77.6 & 5.2 \\
\hline & & Acidic & 89.7 & 10.8 & 109.7 & 11.8 & 97.0 & 12.2 & 86.9 & 12.0 \\
\hline \multirow[t]{2}{*}{ AZA1 } & \multirow[t]{2}{*}{ ESI+ } & Alkaline & 84.1 & 3.8 & 83.5 & 3.8 & $100.6^{\mathrm{a}}$ & 3.6 & 84.6 & 4.5 \\
\hline & & Acidic & 78.2 & 7.2 & 73.6 & 10.7 & 83.7 & 7.5 & 65.5 & 7.6 \\
\hline \multirow[t]{2}{*}{ PTX2 } & \multirow[t]{2}{*}{$\mathrm{ESI}^{-}$} & Alkaline & 93.1 & 6.6 & 67.7 & 13.4 & $114.2^{\mathrm{a}}$ & 11.9 & $106.2^{\mathrm{a}}$ & 11.9 \\
\hline & & Acidic & 101.6 & 11.5 & 106.2 & 12.9 & 85.2 & 14.1 & 86.6 & 15.7 \\
\hline \multirow[t]{2}{*}{ PTX2 } & \multirow[t]{2}{*}{ ESI+ } & Alkaline & 94.3 & 5.4 & 85.4 & 5.4 & $102.9^{\mathrm{a}}$ & 5.1 & $97.0^{\mathrm{a}}$ & 4.9 \\
\hline & & Acidic & 89.1 & 7.2 & 140.2 & 10.8 & 131.8 & 11.7 & 117.4 & 12.4 \\
\hline
\end{tabular}

Numbers given in italics: when RSD above $15 \%$ or when recovery, crude, after SPE or apparent recovery are below $85 \%$ or above $115 \%$

${ }^{a}$ Significantly improved compared to crude extract $(p \leq 0.05)$

\section{Matrix effects in the crude and SPE-purified extracts}

In the crude scallop and oyster extracts substantial ion enhancement was found for OA when run with the acidic
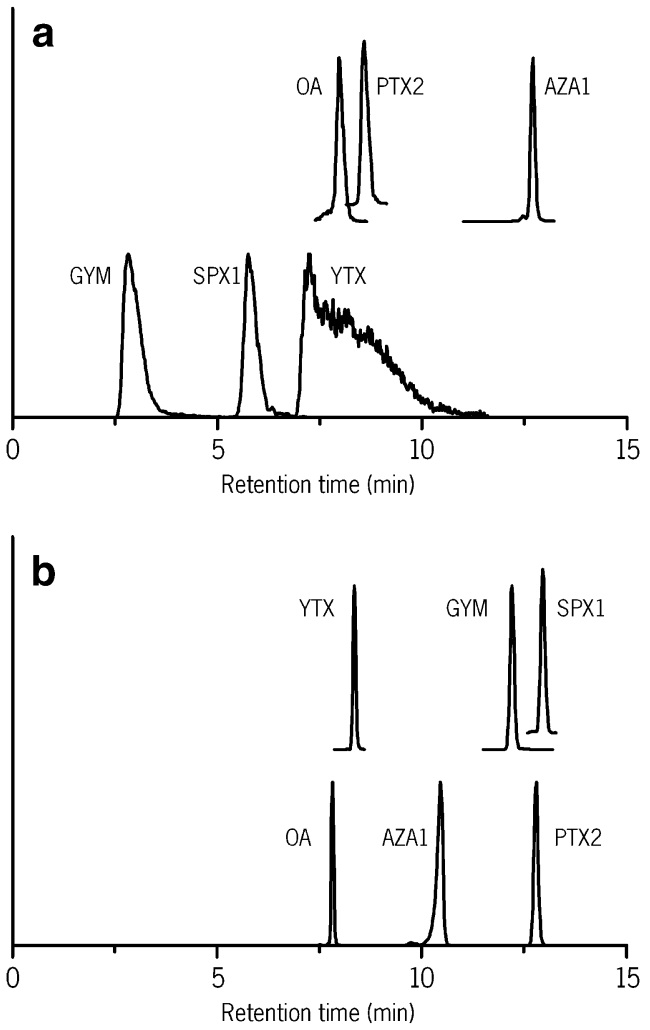

Fig. 6 Analysis of toxins under a acidic conditions and $\mathbf{b}$ alkaline conditions by LC-MS/MS method (Tables 4 and 5). The ion enhancement for OA in the scallop extract was as high as $103 \%$ in $\mathrm{ESI}^{+}$and $29 \%$ in ESI $^{-}$. For OA, when extracts from the different shellfish matrices were analyzed with the alkaline LC gradient severe signal suppression of up to $70-80 \%$ was observed in $\mathrm{ESI}^{+}$, but only minor suppression $(<20 \%)$ was observed in ESI- (Tables 3, 4, and 5). The SPE clean-up reduced the signal enhancement for OA in the samples analyzed under acidic conditions to less than $20 \%$ in $\mathrm{ESI}^{+}$with a large relative standard deviation of $22.8 \%$ and in $\mathrm{ESI}^{-}$the matrix effect was reduced to $<15 \%$ with RSDs below $15 \%$. With the alkaline method, only minor ion suppression or enhancement $(<10 \%)$ was observed, except for mussel and oyster extracts for which severe suppression (40-50\%) was found in $\mathrm{ESI}^{+}$. In $\mathrm{ESI}^{+}$, enhancement and suppression effects for OA are stronger than in $\mathrm{ESI}^{-}$. This is true for both applied methods, but especially for the alkaline method for which significant suppression is observed after SPE clean-up. OA, DTX1, and DTX2 are, therefore, preferably analyzed in the $\mathrm{ESI}^{-}$mode.

For YTX, only moderate matrix effects were observed in the crude extracts (Tables 3, 4, and 5). The largest effect was observed for the mussel extract run under acidic conditions resulting in $25 \%$ ion enhancement. Under alkaline conditions, the oyster extract gave $20 \%$ ion suppression for YTX. SPE clean-up contributed to a reduction of the suppression and enhancement effects for YTX in the various extracts to $15 \%$ for both LC gradients. The only exception was the mussel extract analyzed with the acidic gradient, for which an enhancement of around $20 \%$ was found. For YTX, significantly smaller RSDs were 
obtained with the alkaline method (5.0-6.2\%) than with the acidic method (12.2-19.4\%). This can be attributed to the fact that the peak shape of YTX is much better under alkaline conditions [28].

Suppression effects for AZA1 in the crude extracts were in the order of $20-40 \%$ with the acidic, and 10 $20 \%$ with the alkaline method. After SPE clean-up, still some suppression (20\% in scallop extracts) was found with the acidic gradient while with the alkaline gradient the suppression was reduced to $<5 \%$. For both methods, the relative standard deviations obtained were good $(<15 \%)$ except for the crude scallop extract analyzed under acidic conditions (RSD 35.9\%).

For PTX2, the differences in observed matrix effects in the crude extracts between $\mathrm{ESI}^{+}$and ESI were not as large as for OA. When analyzed under acidic conditions and in $\mathrm{ESI}^{+}$, PTX2 showed signal enhancement of around $40 \%$, while in ESI $^{-}$minor enhancement was observed $(<15 \%)$. When applying the alkaline method, significant ion suppression was observed for PTX2 with both ESI modes, ranging from $15 \%$ for oyster in $\mathrm{ESI}^{+}$to $43 \%$ for the scallop extract in $\mathrm{ESI}^{-}$. In the purified extract, PTX2 revealed ion enhancement of $20-30 \%$ in $\mathrm{ESI}^{+}$under acidic conditions, while in ESI $^{-}$minor enhancement was observed $(<15 \%)$. Relatively high relative standard deviations of more than $15 \%$ were obtained in $\mathrm{ESI}^{-}$, which can be explained by the low sensitivity of PTX2 in ESI. The basic gradient largely removed the matrix effects resulting in ion suppression or enhancement effects of less than $15 \%$ for all matrices in $\mathrm{ESI}^{+}$ and $\mathrm{ESI}^{-}$. Differences in matrix effects observed between the two gradients can be explained by the fact that the alkaline gradient is probably such that the toxin elution occurs outside the elution of the majority of the matrix constituents resulting in less ion suppression and enhancement effects.

In the crude mussel extract, only minor suppression occurred for SPX1 and GYM with both gradients $(<15 \%)$. Surprisingly, for the extract analyzed after SPE the suppression increased to $35 \%$ with the acidic conditions, while for the alkaline method the suppression remained minimal at less than $5 \%$. It can be concluded that SPE clean-up resulted in the reduction of matrix effects for most toxins studied. However, the amount of reduction was variable and depended on the chromatographic conditions used. Overall, the clean-up was more efficient and more reproducible in combination with the alkaline method. As shown in Tables 3, 4 , and 5 most toxins analyzed with the alkaline gradient gave a significant $(p \leq 0.05)$ reduction in matrix effects after SPE clean-up compared to the crude extracts.

\section{Apparent recovery of the SPE method}

The apparent recovery, defined as the combined effect of the SPE recovery and the remaining matrix effects is shown in Tables 3, 4, and 5. In general, an improvement was obtained when the apparent recoveries were compared with the corresponding recoveries obtained from the crude extracts indicating the beneficial effect of applying SPE clean-up for the removal of matrix components likely to induce suppression effects. For the acidic gradient, the apparent recovery varied between $62.5 \%$ for SPX1 and GYM in mussel and $117.4 \%$ for PTX2 in the oyster extract. For the alkaline method, the apparent recovery varied between $77.6 \%$ for YTX in oyster and $100.4 \%$ for YTX in the scallop extract. Furthermore, the RSDs obtained with the alkaline method were significantly better than with the acidic method.

In order to improve the apparent recovery, the apparent recovery should be corrected for the loss of toxins encountered during SPE. There are several methods to correct for these losses. First, a correction factor matching the loss of recovery could be used, which should be determined during validation of the method. The second option is to use matrix-matched standards. When these matrix-matched standards are applied to the SPE procedure, they would give the correction for the recovery of the SPE step.

In general, the overall recovery of the SPE clean-up combined with the alkaline method was more reproducible than with the acidic method.

\section{Conclusion}

The SPE clean-up using Strata ${ }^{\mathrm{TM}}-\mathrm{X}$ cartridges resulted in reduced matrix effects when both acidic and alkaline LC gradients were applied. Moreover, when SPE was used in combination with the alkaline method the matrix effects after SPE were reduced to less than $15 \%$ for all toxins analyzed in their preferred mode regardless of the matrix used. For the acidic method, differences in matrix effects were less substantial between the crude extract and extract after SPE. The matrix effects obtained in crude mussel extracts were in accordance with the results obtained by Fux et al. [26]. Only for two toxins (OA and AZA1) in purified mussel extract were the matrix effects less than $15 \%$. In the present study, the observed RSDs of the results were much smaller with the alkaline method as well $(<15 \%)$.

When the apparent recovery is compared to the crude extract, a significant improvement $(p \leq 0.05)$ was only obtained for a few toxins (Tables 3, 4, and 5). At first sight, one could consider not to implement the SPE procedure. The loss of toxins encountered during SPE (average recoveries around 90\%) attributed to this modest improvement in apparent recovery. However, when the crude extract and the extract after SPE were compared, a 
significant reduction $(p \leq 0.05)$ in matrix effects was obtained for most toxins analyzed by the alkaline method (OA ESI ${ }^{+}, \mathrm{AZA} 1, \mathrm{PTX}_{2} \mathrm{ESI}^{+}$and $\mathrm{ESI}^{-}$, and GYM) and for some analyzed with the acidic method $\left(\mathrm{OA} \mathrm{ESI}^{+}\right.$, and AZA1).

The detection limits of the alkaline and acidic method is as previously published well below the current legislation [12].Therefore, small losses obtained during the SPE will not lead to sensitivity issues during the analysis of marine lipophilic toxins at the current established levels.

Differences observed between the acidic and alkaline chromatographic conditions after SPE clean-up using Strata ${ }^{\mathrm{TM}}-\mathrm{X}$ indicate that the clean-up could possibly still be further improved. This will, however, not be easy because the large range of lipophilicities involved. Analysis of single-toxin groups and after selective SPE clean-up could be considered as an alternative, but obliviously only at the expense of increased analytical turnaround times. The use of the Symbiosis Pharma system for the automated screening of various SPE sorbents was advantageous in this study. With this system, the testing of sorbents including the testing of various wash and elution solvents could be done more effectively compared to the time consuming offline optimization experiments. In summary, this study showed that the use of branded, polymeric SPE sorbents for shellfish extract clean-up has the efficiency to reduce deleterious matrix constituents whilst, in most toxin/ shellfish matrix combinations, maintaining satisfactory reproducible recoveries.

Acknowledgment This research was undertaken with the financial support of the European Commission, within the 6th Framework project 'BIOTOX: Development of cost-effective tools for risk management and traceability systems for marine biotoxins in seafood' Contract no: 514074 (www.biotox.org).

Open Access This article is distributed under the terms of the Creative Commons Attribution Noncommercial License which permits any noncommercial use, distribution, and reproduction in any medium, provided the original author(s) and source are credited.

\section{References}

1. Yasumoto T, Murata M (1993) Marine toxins. Chem Rev 93:1897-1909

2. Toyofuku H (2006) Joint FAO/WHO/IOC activities to provide scientific advice on marine biotoxins (research report). Mar Pollut Bull 52:1735-1745

3. Terao K, Ito E, Oarada M, Murata M, Yasumoto T (1990) Histopathological studies on experimental marine toxin poisoning. 5. The effects in mice of yessotoxin isolated from Patinopecten yessoensis and of a desulfated derivative. Toxicon 28:1095-1104

4. Aune T, Sorby R, Yasumoto T, Ramstad H, Landsverk T (2002) Comparison of oral and intraperitoneal toxicity of yessotoxin towards mice. Toxicon 40:77-82
5. Twiner MJ, Hess P, Dechraoui MYB, McMahon T, Samons MS, Satake M, Yasumoto T, Ramsdell JS, Doucette GJ (2005) Cytotoxic and cytoskeletal effects of azaspiracid-1 on mammalian cell lines. Toxicon 45:891-900

6. Ito E, Satake M, Ofuji K, Kurita N, McMahon T, James KJ, Yasumoto T (2000) Multiple organ damage caused by a new toxin azaspiracid, isolated from mussels produced in Ireland. Toxicon 38:917-930

7. Miles CO, Wilkins AL, Munday R, Dines MH, Hawkes AD, Briggs LR, Sandvik M, Jensen DJ, Cooney JM, Holland PT, Quilliam MA, MacKenzie AL, Beuzenberg V, Towers NR (2004) Isolation of pectenotoxin-2 from Dinophysis acuta and its conversion to pectenotoxin-2 seco acid, and preliminary assessment of their acute toxicities. Toxicon 43:1-9

8. Miles CO, Wilkins AL, Munday JS, Munday R, Hawkes AD, Jensen DJ, Cooney JM, Beuzenberg V (2006) Production of 7epi-pectenotoxin-2 seco acid and assessment of its acute toxicity to mice. J Agric Food Chem 54:1530-1534

9. Richard DJA, Arsenault E, Cembella AD, Quilliam MA (2000) Investigations into the toxicology and pharmacology of spirolides, a novel group of shellfish toxins. In: Hallegraeff GM, Blackburn SI, Bolch CJ, Lewis RJ (eds) Intergovermental Oceanographic Commission of UNESCO, 2001. Hobart, Australia, pp 383-386

10. European Commission (2004) Commission Directive 2004/853/ EC Specific hygiene rules for food of animal origin. Off J Eur Commun L226:22-82

11. Alexander J, Audunsson GA, Benford D, Cockburn A, Cradevi JP, Dogliotti E, Domenico AD, Fernandez-Cruz ML, FinkGremmels J, Furst P, Galli C, Grandjean P, Gzyl J, Heinemeyer G, Johansson N, Mutti A, Schlatter J, Rv L, Peteghem CV, Verger $P$ (2008) Marine biotoxins in shellfish-okadaic acid and analogues. The EFSA Journal 589:1-62

12. Gerssen A, Mulder PPJ, McElhinney MA, De Boer J (2009) Liquid chromatography - tandem mass spectrometry method for the detection of marine lipophilic toxins under alkaline conditions. J Chromatogr A 1216:1421-1430

13. Stobo LA, Lacaze JPCL, Scott AC, Gallacher S, Smith EA, Quilliam MA (2005) Liquid chromatography with mass spectrometry-detection of lipophilic shellfish toxins. J AOAC Int 88:1371-1382

14. McNabb P, Selwood AI, Holland PT (2005) Multiresidue method for determination of algal toxins in shellfish: single-laboratory validation and interlaboratory study. J AOAC Int 88:761-772

15. Fux E, McMillan D, Bire R, Hess P (2007) Development of an ultra-performance liquid chromatography-mass spectrometry method for the detection of lipophilic marine toxins. J Chromatogr A 1157:273-280

16. Ito S, Tsukada K (2002) Matrix effect and correction by standard addition in quantitative liquid chromatographic-mass spectrometric analysis of diarrhetic shellfish poisoning toxins. J Chromatogr A 943:39-46

17. Jorgensen K, Jensen LB (2004) Distribution of diarrhetic shellfish poisoning toxins in consignments of blue mussel. Food Addit Contam 21:341-347

18. Furey A, Brana-Magdalena A, Lehna M, Moroney C, James KJ, Satake M, Yasumoto T (2002) Determination of azaspiracids in shellfish using liquid chromatography/tandem electrospray mass spectrometry. Rapid Commun Mass Spectrom 16:238-242

19. Puente PF, Saez MJF, Hamilton B, Lehane M, Ramstad H, Furey A, James KJ (2004) Rapid determination of polyether marine toxins using liquid chromatography-multiple tandem mass spectrometry. J Chromatogr A 1056:77-82

20. Vale P, Sampayo MAD (2002) Esterification of DSP toxins by Portuguese bivalves from the Northwest coast determined by LCMS - a widespread phenomenon. Toxicon 40:33-42 
21. Van Loco J, Kotterman MJJ, Hess P (2008) Report on results of the validation study (D29), within the 6th Framework project 'BIOTOX: Development of cost-effective tools for risk management and traceability systems for marine biotoxins in seafood' Contract no: 514074

22. Puech L, Dragacci S, Gleizes E, Fremy JM (1999) Use of immunoaffinity columns for clean-up of diarrhetic toxins (okadaic acid and dinophysistoxins) extracts from shellfish prior to their analysis by HPLC fluorimetry. Food Addit Contam 16:239-251

23. Quilliam MA (1995) Analysis of diarrhetic shellfish poisoning toxins in shellfish tissue by liquid-chromatography with fluorometric and mass-spectrometric detection. J AOAC Int 78:555-570

24. Goto H, Igarashi T, Yamamoto M, Yasuda M, Sekiguchi R, Watai M, Tanno K, Yasumoto T (2001) Quantitative determination of marine toxins associated with diarrhetic shellfish poisonning by liquid chromatography coupled with mass spectrometry. J Chromatogr A 907:181-189

25. Moroney C, Lehane M, Brana-Magdalena A, Furey A, James KJ (2002) Comparison of solid-phase extraction methods for the determination of azaspiracids in shellfish by liquid chromatographyelectrospray mass spectrometry. J Chromatogr A 963:353-361
26. Fux E, Rode D, Bire R, Hess P (2008) Approaches to the evaluation of matrix effects in the liquid chromatography-mass spectrometry (LC-MS) analysis of three regulated lipophilic toxin groups in mussel matrix (Mytilus edulis). Food Addit Contam 25:1024-1032

27. Hess P, McMahon T, Slattery D, Swords D, Dowling G, McCarron M, Clarke D, Gibbons W, Silke J, O'Cinneide M (2003) Use of LC-MS testing to identify lipophilic toxins, to establish local trends and interspecies differences and to test the comparability of LC-MS testing with the mouse bioassay: an example from the Irish Biotoxin monitoring programme 2001. In: Villalba A, Reguera A, Romalde JL, Beiras R (eds) Consellería de Pesca e Asuntos Marítimos da Xunta de Galicia and Intergovernmental Oceanographic Commission of UNESCO, 2003. Santiago de Compostela, Spain, pp 57-66

28. Quilliam MA, Hess P, Dell' Aversano C (2001) Recent developments in the analysis of phycotoxins by liquid chromatographymass spectrometry. In: de Koe WJ, Samson RA, van Egmond HP, Gilbert J, Sabino M (eds) Mycotoxins and phycotoxins in perspective at the turn of the century. Wageningen, The Netherlands, pp 383-391 